\title{
O Mestre e o Psicanalista: tecendo laços nas políticas públicas
}

\section{The Master and the Psychoanalyst: weaving ties in policies public}

\section{El Maestro y el Psicoanalista: tejiendo lazos en las políticas públicas}

\author{
Roseane Freitas Nicolau* \\ Universidade Federal do Pará - UFPA, Belém, Pará, Brasil
}

\section{Roberto Calazans**}

Universidade Federal de São João del Rei - UFSJR, São João Del Rei, Minas Gerais, Brasil

\begin{abstract}
RESUMO
A inserção do discurso psicanalítico nas instituições públicas de saúde gera alguns impasses técnicos e éticos ao confrontar a singularidade do "cada um", buscada pela psicanálise com a assistência à saúde regida por políticas públicas de atenção e de cuidados aplicados "para todos" os usuários de determinadas categorias. Isso tem levado muitos psicanalistas a se questionarem sobre pontos importantes dessa experiência, como o lugar do sujeito nos serviços de saúde, cuja emergência fica subsumida pelo discurso do mestre, que estrutura os laços institucionais. Como manter a especificidade da práxis psicanalítica no contexto institucional, em que laços são estruturados pelo discurso do mestre? Como se dão os encontros e desencontros entre os discursos do mestre e do psicanalista? A Psicanálise, consoante a orientação freudo-lacaniana, responde a esses problemas levando em consideração a particularidade do discurso do psicanalista e o tratamento do sujeito do inconsciente a partir daquilo que Lacan chamou de Psicanálise aplicada à terapêutica, o que torna possível a inserção da Psicanálise na instituição.

Palavras-chave: Psicanálise, instituição, discursos, ética, cuidado.
\end{abstract}

\section{ABSTRACT}

The psychoanalytic discourse insertion into public health institutions causes some technical and ethical deadlocks for confronting the singularity of "an individual", that is an aim of psychoanalysis, to the kind of healthcare employed by public policies of attention and care "for all" users of certain categories. This fact has made many psychoanalysts to wonder about important points of this experience, for example the role of subject in healthcare services, whose emergency gets subservient to the master's discourse, which structures the institutional relations. How to keep the specificity of the psychoanalytical praxis in the institutional context, in which bonds are structured by the master's discourse? How do agreements and 
disagreements between discourses of master and psychoanalyst happen? The Psychoanalysis, according to the Freudian-Lacanian orientation, responds to these issues taking into account the analyst's discourse peculiarity and treatment of the subject of the unconscious from what Lacan called psychoanalysis applied to therapy, which makes possible the inclusion of psychoanalysis the institution.

Keywords: Psychoanalysis, institution, discourses, ethics, care.

\begin{abstract}
RESUMEN
La inserción del discurso psicoanalítico en las instituciones públicas de salud genera algunos impasses técnicos y éticos al confrontar la singularidad del "cada uno", buscada por el psicoanálisis con la asistencia a la salud regida por políticas públicas de atención y de cuidados aplicados "para todos" de determinadas categorías. Esto ha llevado a muchos psicoanalistas a cuestionarse sobre puntos importantes de esa experiencia, como el lugar del sujeto en los servicios de salud, cuya emergencia queda subsumida por el discurso del maestro, que estructura los lazos institucionales. ¿Cómo mantener la especificidad de la praxis psicoanalítica en el contexto institucional, en qué lazos están estructurados por el discurso del maestro? ¿Cómo se dan los encuentros y desencuentros entre los discursos del maestro y del psicoanalista? El psicoanálisis, según la orientación freudolacaniana, responde a estos problemas teniendo en cuenta la particularidad del discurso del psicoanalista y el tratamiento del sujeto del inconsciente a partir de aquello que Lacan Ilamó del psicoanálisis aplicado a la terapéutica, lo que hace posible la inserción del psicoanálisis en la institución.
\end{abstract}

Palabras clave: Psicoanálisis, de la institución, discursos, ética, cuidado.

\title{
1 Introdução
}

Atualmente, muitos psicanalistas têm exercido sua práxis em instituições de saúde, nas quais a interlocução com outros profissionais é condição necessária para que seu trabalho seja possível. No diálogo entre profissionais, o encontro entre saberes e práticas de diferentes perspectivas pode suscitar conflitos em relação à orientação do tratamento, em especial no que se refere às políticas que o sustentam. Como manter a especificidade da práxis psicanalítica, quando as práticas institucionais se sustentam em uma política do universal, aplicando protocolos ordenados por tipos clínicos determinados por um saber constituído e organizado? O psicanalista, avesso a tal procedimento, está interessado no saber inusitado que possa se articular no sujeito, apostando que esse mesmo sujeito possa emergir e se implicar com seu sintoma. Como sustentar, nesse contexto, a direção do tratamento analítico sem ceder, com a mudança da técnica, a uma forma assistencial de operar? Não temos resposta, mas tais questões nos convocam a pensar sobre nosso modo de operar nas instituições a partir das ferramentas conceituais que embasam nossa técnica.

Se de um lado a entrada do psicanalista nas instituições atende ao desejo de Freud (1919/1987) de estender o tratamento psicanalítico 
à população para que esta possa dele se beneficiar, de outro, traz o risco de perdermos a especificidade da práxis psicanalítica. Daí a necessidade de pensar sobre o que fazemos nesse contexto, o que, aliás, foi uma preocupação de Freud, que ao enunciar essa possibilidade mostrou-se ao mesmo tempo sensível e cauteloso no que concerne à inclusão de algumas inovações no campo da técnica. Certamente, ele temia os desvios daquilo a que a psicanálise visa: a dimensão ética do sintoma. Por isso, não podemos nos esquecer de que no encontro com outros saberes é preciso manter a especificidade da práxis psicanalítica.

Inicialmente nos perguntamos: se o psicanalista é aquele que se dirige ao sujeito do inconsciente, provocando a produção de um saber singular, haveria lugar para ele em uma instituição marcada pelo discurso médico, que aplica um saber universal, pautando-se na certeza de suas elaborações? Se a posição do médico diante do doente é de quem possui um saber sobre a doença, as instituições do Estado se colocam muitas vezes na mesma posição de responder a todas as questões do sujeito. Ao invés da implicação do sujeito com seu desejo, temos a sua redução a um organismo em nome de um ideal científico. É possível fazer circular o saber em tais condições para que o sujeito possa emergir?

Acreditamos que todo e qualquer serviço público de saúde que oferte modalidades de trabalho psicológico pode se constituir como um potencial espaço de escuta do sujeito do desejo. No entanto, como compatibilizar essa escuta do sujeito em instituições que se pautam por políticas públicas que sempre pensam na direção do todo? No caso de políticas públicas, não podemos nos esquecer da existência de um complicador adicional, que é a própria definição de saúde, a qual se enuncia como a promoção do bem-estar bio-psico-social, elaborada pela Organização Mundial de Saúde (OMS) para regê-las. E em nome desse bem-estar que as políticas públicas apresentam significantes como proteção, assistência e prevenção, colocando-se como agentes do saber que pretende remover a dimensão de verdade do sujeito que o sintoma comporta. Trata-se de uma ética do cuidado, cuja ação assistencialista, na maior parte das vezes, promove um ideal de reparação, saúde e adaptação, provocando no sujeito uma alienação ao saber do outro diante do qual seu saber é desconsiderado. A consequência disso é uma maior dificuldade do sujeito de implicar-se com seu sintoma e responsabilizar-se pelo seu tratamento.

Desse modo, é preciso fazer resistência a uma tal política e é Lacan quem nos ensina que a psicanálise incide sobre o campo da política justamente por interrogá-lo e por expor suas falhas. Por isso, pensamos que a psicanálise deve contribuir também ao esforço coletivo de construir o campo da atenção à saúde, visto que, conforme Lacan (1998b), a psicanálise, além de uma tática e uma 
estratégia, comporta também uma política da qual o psicanalista não pode abrir mão: fazer existir a psicanálise e o sujeito do desejo, e não a redução do mesmo ao registro da cidadania.

O engajamento de psicanalistas, seja no trabalho clínico junto aos sujeitos, seja no trabalho junto à equipe multiprofissional, vem sustentar a importância da dimensão inconsciente do sujeito como eixo do trabalho clínico em instituições. Assim, muitos psicanalistas têm atendido as demandas para intervir no campo social, particularmente na atenção psicossocial em instituições de saúde, de ensino, jurídicas, etc., inseridas no plano das políticas públicas de assistência. É pelo viés dessa prática que discutimos neste artigo o ponto de resistência da psicanálise à política como ideal, a partir da tensão entre políticas públicas universalizantes e clínica nas intervenções do psicanalista no campo social. Como inserir a psicanálise no serviço público de assistência à saúde sem ceder dos seus fundamentos, é o que nos perguntamos frequentemente.

A resposta que nos ocorre é sempre na direção de que para sustentar essa prática é preciso pensar em nossas ferramentas conceituais, estabelecendo a fundamental relação entre teoria e clínica na psicanálise e contextualizando espaços de escuta e de intervenção em instituições, considerando as interlocuções com outros campos disciplinares, sem permitir que os outros discursos, na prática dos serviços, subsumam o psicanalítico. E para tal, é necessário sustentar a psicanálise a partir de sua teoria.

Historicamente, nem sempre foi essa a percepção dos psicanalistas que acreditaram muitas vezes que, na interseção com outros discursos, a psicanálise poderia afrouxar seus fundamentos a fim de se fazer valer de alguma forma. Na contramão dessa ideia, pensamos que é preciso desenvolver cada vez mais o campo teórico-clínico da psicanálise, pois é justamente nesse afrouxamento que se abrem as brechas que podem enfraquecer o discurso do analista ante os outros discursos. A ferramenta conceitual que nos permite pensar a inserção do discurso psicanalítico entre outros é a teoria dos quatro discursos de Lacan por um lado e, por outro, a dimensão do que Lacan chama, em seu Ato de fundação, de psicanálise aplicada à terapêutica. É o que trataremos neste artigo.

\section{Lacan e a Produção dos Discursos}

Lacan elabora a teoria dos quatro discursos para pensar as modalidades de laço social, em que o discurso é introduzido como uma estrutura necessária que ultrapassa a palavra. Lacan propõe quatro discursos como reguladores do laço social que nos auxiliam a refletir sobre o modo de articulação entre o campo do sujeito e o campo do Outro: o do mestre, o da histérica, o do universitário e o 
do psicanalista ${ }^{1}$. Por meio desses discursos, podemos verificar as diferentes posições que um sujeito assume na sua relação com 0 outro. Como diz Alberti (2002, p. 38), "Se o sujeito do discurso (aquele que fala) provoca o laço social, é porque ocupa uma das posições em um desses quatro discursos."

Cada discurso aponta a relação do campo do sujeito com o campo do Outro como condição de estabelecimento do laço social, além de ser representado por um matema, estrutura composta por letras que indicam, ao mesmo tempo, uma articulação e uma impossibilidade entre os campos. Lacan articula os discursos a partir de quatro elementos situados em quatro posições diferentes. Dependendo do elemento que ocupar a posição no discurso, temos uma modificação do discurso em questão. Comecemos, então, estabelecendo as posições que os elementos podem ocupar: agente, outro, produção e verdade. Estes lugares serão ocupados por quatro elementos ou letras:

S1: significante mestre ou significante unário

S2: saber ou significante binário

$\$$ : sujeito dividido ou sujeito barrado

a: objeto a

O S1 representa o significante mestre ou primordial, aquele que funda o sujeito, correspondendo ao significante unário, o elemento que, na cadeia de significantes, sempre representa um sujeito para outro significante, $\mathrm{S2}$, e surge no campo Outro. A consequência é que "[...] isso quer dizer que não há sujeito que gere a si mesmo apesar do Ideal de autonomia do neurótico; surgidos, somos gerados no campo do Outro e devido ao campo do Outro". (Wainsztein, 2001, p. 17).

O S2, por sua vez, é o significante no campo do Outro, também concebido como saber do Outro. Ele abrange todos os significantes que provêm do Outro, assim como se distingue do significante mestre. Corresponde às palavras que surgem antes mesmo do nascimento do sujeito da falta \$, condenando-o a desaparecer da cadeia significante.

Já o sujeito da falta, ou sujeito barrado (\$), surge a partir da intervenção do $\mathrm{S} 1$ no campo já constituído de outros significantes, quer dizer, do S2. Dessa operação, produz-se uma perda, um resto, que constitui o motor para o funcionamento de cada discurso representado por uma letra: o objeto $a$. Dessa forma, o sujeito da falta (\$) é gerado no campo do Outro e pelo campo do Outro.

O objeto a ou mais-gozar corresponde ao objeto que insiste em se repetir. O sujeito neurótico resiste em perdê-lo e, por esse motivo, torna-se um a mais, um excesso de gozo.

Desse modo, podemos notar que a representação de cada elemento 
no que podemos chamar de álgebra lacaniana torna bastante clara a transmissão dos efeitos de um elemento $(\mathrm{S} 1, \mathrm{~S} 2, \$, a)$ sobre os outros, conforme sua posição/lugares na estrutura quartenária dos discursos.

Além do significado que cada elemento ou letra possui no arranjo discursivo, Lacan também faz uso das setas de implicação ou conexão, dispostas entre os quadrantes do algoritmo. A primeira $(\rightarrow)$ parte do agente em direção ao Outro e a segunda $(\leftarrow)$ parte da produção em direção à verdade.

As setas de implicação e conexão cumprem a função de orientar o sentido da cadeia significante e do movimento do quarto de giro circular que promove a mudança de um discurso em outro, tanto no sentido horário (por progressão), como no sentido anti-horário (por regressão), o que viabiliza a permutação circular dos elementos. As barras ( / ) designam o recalque na estrutura significante. É por meio desse quarto de giro que podemos encontrar a passagem de um discurso ao outro e que é importante para pensarmos a tensão entre o discurso do mestre e do psicanalista.

A estrutura de um discurso é formada a partir da relação de um significante com outro significante, sendo as letras ou os elementos dispostos nos discursos resultantes da lógica significante inscrita na linguagem. A passagem de um discurso ao outro opera segundo a permutação dos elementos nos lugares fixos, o que corresponde a um quarto de giro, provocando um movimento circular. O discurso inaugural é o discurso do mestre e todos os demais se configuram a partir de um quarto de giro de seus elementos.

Como nossa proposta é abordar a prática institucional referida ao discurso do mestre e à prática profissional do psicólogo orientado pela psicanálise, abordaremos aqui apenas o discurso do mestre e 0 discurso do analista.

No discurso do mestre temos, no lugar do agente, o significante mestre (S1). No lugar da verdade, o sujeito barrado (\$); no lugar do Outro, o saber (S2) e, no lugar do produto, o objeto a. O significante mestre no lugar do agente submete o outro ao seu discurso, pois o S1 está no lugar de comando. O discurso do mestre representa 0 discurso do poder, da dominação, no qual o significante mestre se dirige ao outro do saber para fazer surgir uma produção. Nisso, pode ser apreendido, ao mesmo tempo, o equívoco contido no fato de existir uma relação de dependência entre o senhor - mestre que sabe - e o escravo - aquele que sabe fazer. A dialética hegeliana do senhor e do escravo pode indicar uma fórmula dialética de estrutura, que mesmo não correspondendo precisamente ao discurso do mestre, ocorre em determinados tipos de discurso, tipos de fala, tipos de posições nas relações sociais das pessoas entre si e também nas instituições, entre os que impedem a escuta do que está para além do sintoma. 
Na composição de uma instituição, pode-se dizer que S1 comanda os sujeitos em posição de escravos. O que assistimos na instituição é o efeito dessa modalidade de laço no sujeito, que espera passivamente uma resposta para o seu sofrimento. Se o saber está no Outro, o sujeito demanda uma resposta para o mal que o acomete, colocandose como depositários do saber que vem do Outro.

Já no discurso do analista, o agente é ocupado pelo objeto a, provocando a divisão do sujeito e instaurando o saber de uma verdade recalcada. Esse discurso se dirige a um saber inconsciente sobre o \$. O saber, S2, está no lugar da verdade de um semi-dizer, uma verdade não-toda, ao passo que o que se produz é o significante-mestre, S1. O analista na posição de a implica o sujeito em fazer emergir seus significantes-mestres que se encontram recalcados.

Assim, o discurso do analista se endereça ao sujeito dividido, enquanto o discurso do mestre se dirige ao Outro enquanto objeto, com um saber absoluto sobre o mesmo. $O$ analista não responde às demandas com o seu saber, mas com seu ato que possibilita ao sujeito um novo encontro com seu desejo.

Para que haja a passagem do discurso do mestre ao do analista é necessário promover um giro que possibilite a mudança de posição no lugar do agente. É esta passagem que buscamos promover na articulação entre os discursos veiculados na instituição. Acreditamos que um elemento importante para fazer esse giro é levar em consideração aquilo que Lacan chama de psicanálise aplicada à terapêutica.

\section{Discurso e Instituição}

Cremos ter agora elementos para pensar a questão dos encontros dos discursos na instituição, a qual é estruturada por um significantemestre no lugar do ideal do Outro, do ideal do que é identificada com - discurso do mestre, que recusa a singularidade do sujeito. 0 domínio muitas vezes assumido pelo profissional sobre o paciente é perpassado por um pressuposto racional que impede a escuta do sujeito, implicando em seu assujeitamento, ao aceitar passivamente as prescrições. Já o avesso do laço social institucional é o discurso do analista, pois a partir desse discurso, o sujeito é convocado a falar e, assim, caberá a ele re(construir) sua própria história (Hoyer, 2010).

Freud (1987b) denominou a instituição de massa organizada, tomando como exemplo o exército e a igreja, pois aquela é a estrutura que presentifica, organiza e funda uma instituição, seja ela qual for. A massa organizada deve sua existência à instauração de regras que são aplicadas a todos os sujeitos submetidos à Lei simbólica na civilização. Essa organização, para a psicanálise 
lacaniana, seja do individual ao coletivo, constitui-se em torno do significante do Nome-do-Pai como significante do Outro, lugar da Lei. Os efeitos particulares no Nome-do-Pai estão atrelados à existência da trama de fios que tecem um conjunto, no qual cada um, depois de ter entrado, terá que encontrar o seu lugar. Com efeito, o significante Nome-do-Pai é o elemento mais essencial na experiência humana, lugar a partir do qual "tudo se irradia e tudo se organiza" (Lacan, 1992a, p. 303).

Portanto, para a psicanálise, qualquer instituição manifesta a relação do sujeito com a Lei e as crenças, mediante as quais a punição se motiva no sujeito. Considerando o sujeito como responsável por sua condição, ele apresenta-se enquanto pivô e efeito dos males próprios assim como dos da instituição. Logo, as estruturas da instituição, tal como o sujeito, são simbólicas, ato e efeito de sua própria condição. De fato, todas as configurações que surgem - políticas, sociais, estéticas, tecnológicas, medicamentosas, pedagógicas, religiosas, sintomáticas, entre outras - são sempre forjadas "pelo e para o sujeito, assim como pela e para a instituição" (Hoyer, 2010, p.104).

No caso da política de saúde mental, verificamos que muitas das dificuldades enfrentadas na condução do trabalho resultam do confronto entre os ideais impressos nos objetivos da política, que privilegia a reinserção social e a conquista dos direitos de cidadania de uma população excluída do convívio social por séculos de tratamento asilar. Privilegia, ainda, as possibilidades concretas dos usuários responderem a esses ideais. As novas diretrizes de cuidado nem sempre alcançam os efeitos esperados, nesse contexto, a clínica ganha relevância como trabalho que se faz com o sujeito, que é sempre singular e não pode ser norteado por imperativos universalizantes.

A clínica se situaria, em princípio, como uma oposição à política identificada aos ideais, na medida em que, como tratamento, é oferecida a cada sujeito. Aí poderíamos pensar numa política da psicanálise relativa ao âmbito público de transformação das instituições?

Observamos que esse campo é atravessado por certa tensão entre a política e a clínica, que pode, a princípio, ser considerada como necessária, pois resulta dos encontros e desencontros entre duas dimensões indispensáveis: a política de saúde de caráter universalizante, que sustenta as práticas no âmbito das instituições, através do estabelecimento de uma série de normas gerais definidoras de objetivos, orientações, competências e formas de gestão; e o trabalho efetivo que a equipe de cada serviço desenvolve com a população assistida, que não pode desconsiderar a singularidade de cada sujeito que busca tratamento em virtude de sofrimento psíquico ou doenças. 
É nessa última dimensão que a clínica encontra o seu lugar, pois ela estará sempre aberta ao imprevisível do sujeito, fugindo ao universal das normas e portarias que definem os novos modelos institucionais.

Se no contexto da política de saúde mental é difícil ouvir o sujeito, no hospital não é diferente. O hospital é um espaço institucional no qual se fazem presentes diferentes especialidades médicas, que objetivam diagnosticar e tratar as doenças para alívio da dor e do sofrimento em geral. Mais especificamente, um Hospital Universitário é um centro de atendimento médico, cujo objetivo é prestar serviços à comunidade, além de auxiliar e participar da formação teórico-prática de discentes da área da saúde. Vale ressaltar ainda que um Hospital Universitário, mesmo estando voltado para a formação de estudantes em diversas outras áreas, como enfermagem, fisioterapia, serviço social, psicologia, etc., delega à medicina um lugar central ao qual são direcionados todos os outros serviços. A medicina coloca-se, nesse contexto, como uma pretensa panaceia para todos os males físicos, morais e psicológicos demandados pelos pacientes.

Com isso, o discurso válido sobre a doença seria a palavra do médico, que tem o saber sobre o processo de adoecimento. Ocorre que muitos quadros clínicos não respondem positivamente aos tratamentos médicos, apontando para a necessidade da introdução de um outro saber que possa acolher os aspectos subjetivos implicados com a doença e que são, em muitos casos, responsáveis pela evolução do quadro clínico.

É a possibilidade de inserção desse outro saber no hospital, particularmente o psicanalítico, que nos impõe trabalho, experimentar, ver a melhor forma de fazer sem entrar em conflito com os demais profissionais. Afinal, para a psicanálise o importante é que o sujeito fale. É preciso permitir ao sujeito falar, recusando o lugar de objeto que the é delegado. É justamente a esse lugar que o paciente é endereçado na instituição. Essa alienação ao Outro é favorecida pelo discurso do profissional que sabe o que o sujeito tem e responde do lugar do mestre. É aí que o psicanalista pode avaliar a melhor forma de introduzir a dúvida sobre o fazer.

Em outras palavras, o psicanalista, ocupando o lugar de objeto a, depois de ter feito seu próprio percurso analítico, questiona, convoca - sujeito, \$, para que este trabalhe e produza seus significantes mestres, (S1), tendo o saber como verdade (S2), saber que não deixa de implicar a psicanálise como teoria da clínica. Com efeito, o saber em jogo no discurso do analista diz respeito ao saber do próprio sujeito. Por isso, esse discurso está em contraponto ao discurso do mestre, justamente porque, neste, trata-se do saber para e sobre o mestre. Já no discurso do analista, o sujeito, convocado a falar (fale livremente) e caberá a ele reconstruir a produção que lhe é própria. O sujeito questionado fabrica o seu produto, que são os seus significantes. 
O analista é norteado pela ética do bem-dizer e convida o sujeito a construir um saber a fim de lidar melhor com seu sintoma. Nesse sentido, o analista como dejeto ocupa o lugar de agente que causa o desejo de saber no outro, saber sobre aquilo de que se queixa. Como fazer furo no saber médico para permitir que o sujeito construa um saber sobre a sua verdade?

Do ponto de vista médico, o diagnóstico, fundamentado nos sinais e sintomas passíveis de observação, funciona como indicador de orientação do tratamento. Dessa forma, o sujeito, reduzido a um diagnóstico descrito no manual médico, é destituído de qualquer referência que lhe diga respeito de modo singular. Assim, se o objeto de investigação da medicina é a doença, esta exclui não só o sujeito afetado por sua divisão, como o próprio sujeito que concebe, que passa pela noção de indivíduo. Em contraponto, a psicanálise, por colocar seu acento no sujeito, pode ser capaz de transmitir sobre este um saber desconhecido por outros discursos, qual seja, o de ser marcado pelo inconsciente.

A subjetividade excluída do discurso médico é privilegiada no discurso psicanalítico, já que é a possibilidade de articulação entre sintoma e história do sujeito. A clínica psicanalítica sugere não haver nenhum diagnóstico, ou qualquer outro saber determinado que informe mais sobre o sujeito do que sua fala. A partir da fala é que se pode ter acesso à realidade psíquica, à posição discursiva do sujeito.

Se a psicanálise inicia-se a partir da prática médica, faz também uma ruptura com esse discurso para instaurar um discurso próprio, uma outra clínica. Tal rompimento ocorre quando Freud percebe que seu instrumento de saber não dá conta das manifestações de suas pacientes. Se as histéricas escaparam ao saber da medicina é porque algum enigma se constituiu das manifestações que elas apresentavam. Dessa maneira, pode-se dizer que a psicanálise surge dos furos do saber médico, ou seja, de um ponto limite da medicina. Freud inaugurou com a psicanálise uma clínica, através de um novo método para tratar do sofrimento psíquico, acrescentando um saber, ainda não sabido. Contudo, se trouxe uma luz a essa clínica, permitindo alívio de sintomas, isso não implicou dar conta dos furos. De outro modo, são justamente esses furos que passam a vigorar em sua teoria e prática, uma vez que a marca da incompletude do sujeito é para o discurso psicanalítico uma marca absolutamente operante.

Para nós, psicanalistas, o inconsciente é uma hipótese a ser comprovada em cada análise, pois a atualidade tende a recalcá-la e a virar as costas para o desejo que aí se manifesta. E ele se manifesta por meio do sintoma, que como disse Lacan, "é o significante recalcado da consciência do sujeito. Símbolo escrito na areia da carne e no véu de Maia" (Lacan, 1998a, p. 282). Daí o sintoma ser um monumento histórico, um marco da história do sujeito - ele é uma mensagem histórica da alienação do sujeito aos significantes do 
Outro. Portanto, o sujeito deve bem dizer o seu sintoma e nós analistas, acolhê-lo.

Mas como fazer isso no âmbito institucional?

\section{Confrontos Discursivos na Instituição e a Psicanálise Aplicada à Terapêutica}

Conforme dito acima, a instituição de saúde é marcada pelo discurso da medicina, que identificamos com o discurso do mestre, esse que estrutura os laços sociais institucionais. A partir disso, perguntamos: haveria possibilidade de aplicar a psicanálise no cotidiano de instituições reguladas por políticas de saúde? Dito de outra forma, como promover nesse tipo de instituição giro necessário para que 0 discurso analítico possa operar, a fim de permitir o surgimento do sujeito, identificado como doente, louco, marginal, usuário, beneficiário, entre outras denominações?

A prática institucional alimenta-se do ideal de saúde para todos, em que o sofrimento do sujeito é acolhido por uma política que se tece apoiada na aplicação de tecnologias desenvolvidas pelo Ministério da Saúde para atender às necessidades dos usuários. As chamadas tecnologias da saúde incluem procedimentos técnicos aplicados por normas estabelecidas em nome do sucesso dos atendimentos, visando uma política de resultados. Desse modo, o profissional, munido de um saber técnico, encontra-se na posição de mestria, capaz de salvar o sujeito de suas mazelas. Por sua vez, alienado na sua condição de vítima, o usuário é colocado na posição de sujeito / objeto de cuidados.

Por outro lado, devemos considerar que esse discurso se dá no âmbito de políticas públicas. E devemos, anteriormente, ter uma noção clara do que seja política pública. De acordo com Souza (2007), podemos denominar política pública como campo do conhecimento capaz de analisar as ações do governo e, quando necessário, propor mudanças nessa direção.

Pontes et al. (2014) afirmam algo importante sobre o termo política nesse campo:

Acreditamos que o uso do termo política não é gratuito. E como um termo especifica um conceito que delimita um campo de ação e um campo de debate, nos deparamos com algumas questões relevantes para essa discussão: a questão da política em seu sentido mais amplo. Assim, as políticas públicas determinam um campo de ação que deve ser pensado a partir da dimensão do laço social, dos meios de convivência a serem pensados ou desejados. Estas ações da política pública se dão no espaço da Pólis: espaço de convivência entre os diversos 
cidadãos em que diversos desejos se entrecruzam. Desejos que apontam para uma dimensão administrativa da política, mas que demandam também uma ética que se dê para além da mera gerência de recursos; que demandam também pensar, debater as finalidades de tais recursos e o desejo que sustenta tal política. E a partir desta definição e reflexão sobre este campo que almejamos explicitar a discussão (Pontes et al., 2014, p.262).

Ora, nessa perspectiva, vemos claramente que nesse campo de políticas públicas, por mais que seja um campo ligado às instituições vinculadas ao discurso do mestre, há brechas para fazer o quarto de giro e sustentar uma ação endereçada ao sujeito do inconsciente.

Vale sublinhar que é próprio da política de saúde tomar partido em função de um ideal a ser alcançado. Assim, ofertam-se bens, estabelecendo uma série de normas gerais que definem objetivos, orientam competências e formas de gestão aos usuários, que devem consumi-los para atingir a harmonia de uma vida saudável. Com isso, temos uma política de caráter universalizante, que sustenta as práticas no âmbito das instituições.

Essa não é a visada da psicanálise, que toma posição em função de uma ética contrária aos avatares da identificação. No Seminário 7, Lacan (1987) afirma que a ética da psicanálise não é aquela que incide sobre a arrumação, a ordenação dos chamados serviços dos bens. A psicanálise trabalha a partir da fala, apostando na diferença e na particularidade de cada caso, e não tem como parâmetro valores universais. Como é possível ao psicanalista sustentar a singularidade em meio a uma política que estabelece um ideal? Que elementos estão em causa em clínicas que tentam dar conta de uma demanda social? Qual a clínica possível em situações em que a demanda de atendimento não parte necessariamente do indivíduo e onde o lugar do sujeito se confunde com o do excluído ou o do desamparado?

Um dos nossos questionamentos refere-se ao lugar do sujeito nos serviços de saúde, na tensão existente entre o discurso médico e o discurso psicanalítico. Há nesse confronto uma tensão discursiva que gera inúmeras dificuldades enfrentadas pelos psicanalistas que avançam na direção do que Lacan (2003a) designou psicanálise aplicada à terapêutica, ao exercer sua prática em instituições. Como isso pode se realizar? Como se dão os encontros e desencontros entre o discurso do mestre e o discurso psicanalítico? Quais as possibilidades de transmissão da operação analítica sem que o psicanalista precise reivindicar a sua especificidade? Como podemos pensar a direção do tratamento no espaço coletivo gerido por uma política contrária à singularidade? E qual a relação da psicanálise aplicada à terapêutica com a psicanálise pura? 
É em seu Ato de fundação da Escola Francesa de Psicanálise, que Lacan (2003a) apresenta três seções, a saber: seção de psicanálise pura, seção de psicanálise aplicada e seção de recenseamento do Campo Freudiano. Dessas três nos interessam aqui somente as duas primeiras. A psicanálise pura representaria a "práxis e doutrina da psicanálise propriamente dita" (Lacan, 2003a, p 236). Entende-se como psicanálise pura o tratamento levado até a sua conclusão, que seria a cura e a passagem do analisando ao estatuto de analista. De fato, a preocupação com a formação do analista fica evidente nessa primeira seção, em que Lacan discute questões relativas à transmissão da doutrina e à importância da supervisão. Já a psicanálise aplicada, indica uma preocupação, não propriamente com a formação do analista, mas antes, com o cuidado terapêutico e com a clínica médica. Lembrar que psicanálise pura e psicanálise aplicada têm uma ligação indissolúvel é importante no cenário atual, uma vez que a crescente presença de psicanalistas nas instituições de saúde no Brasil exige que se pense que tipo de prática é possível nesse contexto específico. Trata-se de uma psicanálise aplicada, uma vez que se reporta a uma aplicação da psicanálise à terapêutica.

Um dos sentidos de psicanálise aplicada à terapêutica toma como referência o tipo de enquadre utilizado. Designa então qualquer modalidade de tratamento que não se encaixe no setting clássico, tal como estabelecido por Freud. Recordemos que o dispositivo clássico opera conforme alguns parâmetros, dos quais se destacam: 1) a regra da associação livre, 2) a condução do tratamento pelo analista como responsável único, 3 ) as intervenções utilizando como instrumento privilegiado a fala.

Em contraposição a esse enquadre tradicional, lançou-se mão posteriormente de uma ampliação da clínica, visando adequá-la aos casos em que por diversas razões aqueles padrões não puderam ser atendidos. Assim, aqueles parâmetros foram sendo revistos conforme as necessidades impostas pela experiência. Tomemos como exemplo a necessidade de se flexibilizar a regra da associação livre ao contexto da escuta de crianças, desafio ao qual respondeu Melanie Klein (1980) com a invenção da técnica do brinquedo. A clínica de crianças nos fornece ainda uma outra situação pouco convencional, que é a escuta dos pais do sujeito (Kupfer, 2000).

Outra situação de modificação de enquadre foi imposta por alguns casos de psicose e pelo autismo, em que o que teve de ser revisto foi o formato consagrado no qual o analista representa o único responsável pela condução do tratamento. Naqueles pacientes, 0 Outro se constitui como um ponto de certeza, sendo seu saber tão consistente que não deixa ao sujeito outra alternativa senão ocupar a posição de objeto. Num esforço para promover uma esquize, uma divisão do lugar do Outro, esvaziando assim seu poder letal, surgiu entre os lacanianos a ideia da prática entre vários (Di Ciaccia, 2003, 
p. 38), uma modalidade de tratamento feita em equipe, que não permite a ninguém ocupar o lugar do saber.

As instituições constituem um problema não só por exigirem uma necessidade de adequação do dispositivo clínico, mas por colocarem um desafio para que esse ajuste não se transforme em corrupção dos princípios da análise. Nesses espaços, os analistas têm encontrado dificuldades para exercer sua prática, uma vez que as instituições funcionam de acordo com uma orientação distinta da ética da psicanálise. As instituições, em sua maioria, funcionam segundo o discurso do mestre, aquele que, segundo Lacan (1992b), trabalha para que as coisas funcionem bem, para que tudo ande em ordem, pressupondo um ideal normatizador. Exige-se, nesses espaços, que 0 psicanalista seja o detentor de uma competência que o capacita a intervir a partir de um saber prévio sobre o sujeito. Não bastando ter que demonstrar uma suposta expertise, o profissional se vê na delicada obrigação de mostrar resultados, que devem ir à direção de um sujeito 'saudável', aqui entendido como alguém que oferece o mínimo de transtorno possível. Sofrendo a pressão de outras classes profissionais e do poder público a fim de se mostrar produtivo ou eficaz, o trabalhador da área da saúde encontra dificuldade em sustentar o discurso do analista, discurso avesso ao do mestre, justamente por localizar o saber do lado do sujeito (Lacan, 1992b).

Pierre Naveau (2007) discute a disseminação da psicanálise aplicada à terapêutica nas instituições, advertindo para a exigência ética de que a psicanálise aplicada à terapêutica seja psicanálise, embora o efeito terapêutico seja levado em conta. Que se trate de psicanálise e não psicoterapia. "Afirmamos haver uma separação nítida a ser operada entre a psicanálise aplicada à terapêutica e a psicoterapia" (Naveau, 2007, p.9). Justamente porque representa um desafio à psicanálise, ao exigir uma readequação do modelo antigo, a aplicação a instituições coloca em xeque os standards, os padrões estereotipados que o clínico pode assumir. Romildo Barros (2003) define o standard de modo pejorativo, como um modelo representado pelos comportamentos rituais que permitem, quando tomados em conjunto, reconhecer um psicanalista e situá-lo em um coletivo. A norma termina por elevar o modelo ao plano de regra universal, dessa forma, quem não segue tal modelo não obtém reconhecimento. Por isso, é preciso repensar a prática fora do standard, mas sem abrir mão dos princípios da psicanálise. A diferença é que o standard representa o que se repete sem invenção, a reprodução do mesmo, ao passo que o princípio se refere à singularidade, ao caráter único e irrepetível de um objeto ou ato (Barros, 2003). Portanto, de acordo com Bastos e Freire (2005), se um princípio não é um padrão de conduta no tratamento, entre o standard e o princípio não pode haver coincidência. 
Mas o que está em jogo então na psicanálise aplicada à terapêutica? Em que ela difere da psicoterapia? E em que ela se aproxima? Para esboçar um princípio de resposta, vejamos primeiro a diferença entre a psicanálise e a psicoterapia. De acordo com Naveau (2007), a psicoterapia visa à identificação, àquilo pelo qual a identificação é tornada possível, ou seja, à instituição do sujeito. A psicanálise tende para a desidentificação, destituindo o sujeito. Ela conduz o sujeito à sua divisão, em vez de harmonizá-lo na busca de uma síntese unificadora.

Segundo Alexandre Stevens (1999), a psicanálise é o contrário de uma psicoterapia, uma vez que a psicoterapia está fundada sobre uma relação em que a imagem do outro dominaria o Eu do sujeito. "Seu campo de ação [o da psicoterapia] pode assim ser definido, a partir da psicanálise, como operando sobre o que nós chamamos dialética intersubjetiva imaginária enquadrada por elementos simbólicos" (Stevens, 1999, p.16).

Questionado sobre a diferenciação entre a psicanálise e a psicoterapia, Lacan (2003b) responde que, na medida em que o inconsciente está implicado, existem duas vertentes da linguagem: a do sentido e a do signo. A vertente do sentido é aquela que está do lado da sugestão, que se faz passar pelo bom senso, tido aqui como senso comum. Para Lacan é aqui que a psicoterapia estanca, não porque não exerce um certo bem, mas por ser um bem que leva ao pior: "(...) daí o inconsciente (...) lembra-nos que à vertente do sentido que nos fascina na fala (...) o estudo da linguagem opõe a vertente do signo" (Lacan, 2003b, p.513).

A psicoterapia estaria situada na vertente do sentido e a psicanálise na vertente do signo. Segundo Elia (2006), este pior apontado por Lacan é o resultado da operação pela qual o Outro, como destinatário da demanda sempre terapêutica, se põe em posição de responder a ela de modo provedor, impedindo que o sujeito faça a experiência de sua castração: "Se nos abstemos de fazer o melhor pelo sujeito, podemos, por isso mesmo, abster-nos de levá-lo ao pior" (Elia, 2006, p. 53).

De acordo com Naveau (2007), o movimento da psicanálise consiste em girar em torno de um furo. E Lacan chama esse furo de "nãosentido da relação sexual" (Lacan, 2003b, p. 512).

A orientação da psicanálise não é em direção ao sentido, ao ideal ou à norma visados pela sugestão, mas em direção ao gozo e a considerar o sintoma como satisfazendo alguma coisa. Eis aqui em que a referência ao sintoma implica uma escolha política, ou seja, uma escolha que se orienta a partir da política lacaniana. A escolha proposta ao praticante é: ou bem ir na direção do sentido e do imaginário, ou bem ir na direção do 
gozo e do real. A orientação lacaniana toma o partido do real contra o imaginário (Naveau, 2007, p.7).

Sempre tendo em mente a distinção entre psicanálise e psicoterapia, voltemos a nos questionar: como praticar a psicanálise em instituições, respeitando seu alvo terapêutico, mas sem fechar a abertura para a psicanálise pura? Justamente pelo fato de a psicanálise em instituições ter algumas especificidades - a tensão entre discurso do mestre e o discurso analítico, dificuldades do manejo do tempo, relações transferenciais com a instituição atravessando a relação transferencial com o analista, trabalho em equipes multidisciplinares - que o objetivo terapêutico não pode perder de vista os fins da psicanálise.

\section{Considerações finais}

Conforme dissemos acima, a posição médica diante do doente é de quem possui um saber sobre a doença. Quando o saber médico falha em responder ao sofrimento do corpo, o saber psicológico é convocado. Assim, a partir do fracasso, percebe-se que a ordem médica não pode imperar sozinha, necessitando da introdução de outra ordem. Dessa forma, abre-se um espaço na instituição para o discurso psicanalítico. É nesse ponto que os psicanalistas procuram inserir o dispositivo analítico com sua ética própria por intermédio de uma clínica que visa o sujeito e não sua doença, o sujeito que não pode ser tratado pelo saber médico, o sujeito que traz em si sua essência de faltante. É o sujeito do inconsciente em sua dimensão de alienação ao Outro.

A psicanálise, através de seu discurso, vem a responder ao fracasso do saber médico introduzindo uma tensão entre o discurso do mestre e o discurso do psicanalista. Afinal, como demonstramos no decorrer do texto, a psicanálise vai apostar que esse fracasso é a possibilidade do sujeito se haver com algo de sua verdade e que se apresenta a partir dos sintomas psíquicos. Desse modo, a psicanálise não irá visar o apagamento desse sintoma, mas implicará o sujeito em relação a ele, o que traz uma ética distinta daquela que muitas vezes sustentas as políticas públicas quando elas visam somente a erradicação do sintoma: a ética do desejo. Desse modo, vemos que há possibilidade de trabalho do psicanalista nas instituições de saúde nesse entrecruzamento de discursos quando emerge o sujeito do inconsciente e o psicanalista é convocado a operar na dimensão da psicanálise aplicada à terapêutica. 


\section{Referências}

Alberti, S. (2000). Psicanálise: a última flor da medicina. In Alberti, S. \& Elia, L. (Org.) Clínica e pesquisa em psicanálise. (pp. 3755). Rio de Janeiro: Rios Ambiciosos.

Barros, R. (2003). Sem standard mas não sem princípio. In: Harari, A.; Cardenas, M.; Fruyer, F. (Orgs.) Os usos da psicanálise (pp. 39-48). Rio de Janeiro: Contracapa,

Bastos, A.; Freire, A. B. (2005). A prática entre vários: princípios e aplicação da psicanálise. In: Santos, T. C. (Org.). Efeitos terapêuticos na psicanálise aplicada (pp. 93-109). Rio de Janeiro: Contra-capa.

Di Ciaccia, A. (2003). Inventar a psicanálise na instituição. In: Harari, A; Cardenas, M.; Fruyer, F. Os usos da psicanálise (pp. 33-38). Rio de Janeiro: Contracapa.

Elia, L. (2006). O começo da análise não pode fazer com que a neurose comece a cessar. In: Alberti, S.; Figueiredo, A. C. (Orgs.). Psicanálise e saúde mental: uma aposta. (pp. 47-54). Rio de Janeiro: Companhia de Freud,

Freud, S. (1987a). As perspectivas futuras da terapia psicanalítica. In Edição Standard Brasileira das Obras Psicológicas Completas de Freud. Vol. XVII (pp. 199-211). Rio de Janeiro: Imago. (Trabalho original publicado em 1919).

Freud, S. (1987b). Psicologia de grupo e análise do ego. In Edição Standard Brasileira das Obras Psicológicas Completas de Freud, Vol. XVIII. (pp. 43-90). Rio de Janeiro: Imago. (Trabalho original publicado em 1921).

Hoyer, C. (2010). A função paterna na instituição: do individual ao coletivo. Rio de Janeiro: Garamond.

Klein, M. (1980/1955). A técnica psicanalítica através do brinquedo. In: Klein, M.; Heimann, P. \& Money-Kyrle, R. M. (Orgs.). Novas tendências na psicanálise (2a ed., pp. 25-48). Rio de Janeiro: Guanabara/Koogan.

Kupfer, M. C. (2000). Notas sobre o diagnóstico diferencial da psicose e do autismo na infância. In: Revista de Psicologia USP, São Paulo, v. 11, n. 1. Disponível em http://www.scielo.br/scielo. Acessado em: 16 de jun. de 2014.

Lacan, J. (1987). O seminário, Livro 7: a ética da psicanálise. Rio de Janeiro: Jorge Zahar. (Seminário ministrado em 1959-1960).

Lacan, J. (1992a). O seminário, Livro 3: As psicoses. Rio de Janeiro: Jorge Zahar. (Seminário ministrado em 1955-1956).

Lacan (1992b). O seminário, Livro 17: O avesso da Psicanálise. Rio de Janeiro: Jorge Zahar. (Seminário ministrado em 19691970).

Lacan, J. (1998a). Função e campo da palavra e da linguagem em psicanálise. In: Lacan, J. Escritos. (pp. 238-324). Rio de 
Janeiro: Jorge Zahar, 1998/1953. (Trabalho original publicado em 1953).

Lacan, J. (1998b). A Direção do Tratamento e os Princípios de seu poder. In: Lacan, J. Escritos. (pp.591-652). Rio de Janeiro: Jorge Zahar. (Trabalho original publicado em 1958).

Lacan, J. (2003a). Ato de fundação. In: Lacan, J. Outros Escritos. (pp.235-247). Rio de Janeiro: Jorge Zahar. (Trabalho original publicado em 1964).

Lacan, J. (2003b). Televisão. In Lacan, J. Outros Escritos. (pp. 508 543). Rio de Janeiro: Jorge Zahar Editor. (Trabalho original publicado em 1973).

Naveau, P. (2007). A psicanálise aplicada ao sintoma. In: E. C. F (Org.) Pertinências da psicanálise aplicada. (pp. 09-16). Rio de Janeiro: Forense Universitária.

Pontes, S., Lopes L., Santos, L.M., Calazans, R. (2014). Implantação de políticas públicas em saúde mental: o caso de São João Del Rei. In: Gerais: Revista Interinstitucional de Psicologia, Juiz de Fora, v. 7, n. 2, dez. Disponível em: http://pepsic.bvsalud.org/scielo. Acessado em: 25 mar. 2015.

Souza, C. Estado da arte da pesquisa em políticas públicas. In.: Hochman, G. ; Arretche, M.; Marques, E. (org.) Políticas públicas no Brasil. Rio de Janeiro : Editora FIOCRUZ, 2007. p.65-86

Stevens, A. (1999). A psicanálise é o contrário de uma psicoterapia. In: VI Jornada da Escola Brasileira de Psicanálise. Salvador: [S.I.]. Mimeografado.

Wainsztein, S. (2001) O discurso do Mestre. In: VEGH, I. (Org.) Os Discursos e a Cura. (15-37). Rio de Janeiro: Companhia de Freud.

\section{Endereço para correspondência \\ Roseane Freitas Nicolau}

Universidade Federal do Pará

Faculdade de Psicologia (IFCH)

Rua Augusto Corrêa, 1, Campos do Guamá (Núcleo Universitário), CEP 66075-900,

Belém - PA, Brasil

Endereço eletrônico: rf-nicolau@uol.com.br

\section{Roberto Calazans}

Universidade Federal de São João del Rei

Departamento das Psicologias

Praça Dom Helvécio 74, Dom Bosco, CEP 36301-160, São João Del Rei - MG, Brasil

Endereço eletrônico: roberto.calazans@gmail.com

Recebido em: 19/05/2015

Reformulado em: 15/09/2015

Aprovado em: 19/11/2015 


\section{Notas}

${ }^{1}$ Em uma conferência em Roma (1974) intitulada a Terceira, Lacan falará de um quinto discurso - o discurso do capitalista. Não abordaremos esse discurso uma vez que ele escapa ao escopo desse artigo.

* Psicóloga, Psicanalista, Mestre em Antropologia, Doutora em Sociologia, Professora Associada III do Programa de Pós-Graduação em Psicologia da UFPA. Pesquisadora do GT ANPEPP Psicanálise, Política e Clínica e membro da Escola de Psicanálise Letra Freudiana do Rio de Janeiro.

** Psicólogo, Mestre em Teoria Psicanalítica, Doutor em Teoria Psicanalítica, Professor Associado III do Programa de Pós-Graduação em Psicologia da Universidade Federal de São João del Rei. Membro do Núcleo de Pesquisa e Extensão em Psicanálise. 